\title{
RANDOM NOTES FROM THE SECRETARIAT
}

At this point in the yea $r$ we a re looking forward to our many and va ried summer activities and wishing the best of success to our many members in various parts of Canada, who are making preparations for them. These activities include the June meetings in conjunction with the Royal Society of Canada in Quebec, the Summer Research Institute in Kingston, the Summer Sessions in Vancouver, Montreal and Halifax, and the Seminar, Colloquium and Congress in Saskatoon.

A final notice giving the programme of the June meetings will be sent to each member as soon as all details a re completed, and registration forms will be sent to heads of departments as soon as they are received from the Conference Committee in charge of arrangements at Laval University. Members of university staffs may then obtain the se forms from the heads of their respective departments. Others who wish to attend will be able to obtain them by writing to the Sec reta riat.

The Summer Research Institute is looking forward to another successful session. Application forms were sent to each member in Canada, although they we re somewhat delayed pending a decision regarding the stipend for fellows. Professor R. L. Jeffery, the director, will be present for the first half of the period, and will then return to Nova Scotia to take part in the Congress Summer School in Halifax for secondary school teachers of mathematics. Mention should be made here of the excellent work of Professor H. W. Ellis of Queen's University, Secretary of the Institute, who took charge of the administration while the director was in Nova Scotia during the latter part of the Institute.

A report on the Congress Summer School in Halifax was given in the previous issue of the Bulletin. The School will be conducted again this year under the same grants from the Province of Nova Scotia and the International Nickel Company. Furthermore, progress has been made towards setting up a specialist certificate on the basis of minimum qualifications, as outlined in the previous is sue.

The Summer Seminar at the University of Montreal was more successful than had been anticipated. The guest lecturers with their subjects were as follows: 
Professor J. L. Lions

University of Paris

Problèmes aux limites dans les

équations aux dérivées partielles

Professor Lucien Waelbroek

University of Brussels

Théorie des algèbres de Banach et des algèbres localement convexes

There were two Canadian lecturers:

Professor M. L'Abbé

University of Montreal

Théorie des fonctions récursives et applications métamathématiques

Professor J. M. A. Ma randa

University of Montreal

Introduction a I' algèbre homologique.

The fifty-one participants came from the following provinces and the United States:

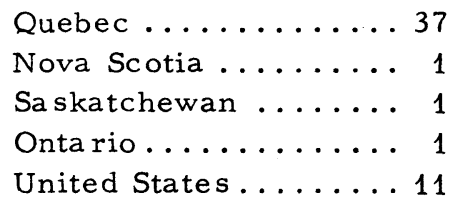

English speaking participants we re assisted by the distribution of mimeographed notes in advance of the lectures. These notes can be purchased from the Department of Mathematics, University of Montreal, Box 6128, Montreal, Quebec. The Seminar will continue this year under a grant from NATO. Further details a re given in the following pages.

The Summer Session in Mathematics at the University of B ritish Columbia increased in number of participants and a furthe $r$ increase is anticipated in 1963. Two courses were offered during the eight weeks ${ }^{1}$ duration:

Professor M. Benedicty

University of British Columbia Analysis

Professor S. Kobaya shi

University of British Columbia Differential Geometry

In addition, the Department offered non-credit seminars in both Pure and Applied Mathematics. The fifteen students from the following provinces and the United States were in attendance: 


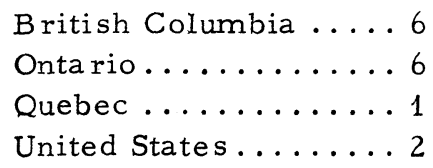

The slate of lecturers for the 1963 biennial seminar is now completed as follows:

\section{Research Lecturers:}

Professor R. H. Bruck United States

Professor K. Kuratowski Poland

Professor G. Pickert Ge rmany

Professor E. M. Wright Scotland

\section{Instructional Lecturers:}

Professor A. L. Dulmage Univ. of Manitoba

Professor A. P. Guinand Univ. of Sa skatchewan

Professor W. T. Tutte Univ. of Waterloo

Professors R. G. Stanton and D. A. Sprott Univ. of Wate rloo
A topic on combinatorial mathematics

Semi-continuity in topology

Projective Planes

Partitions

Combinatorial problems related to graph theory and linear programming

Topic to be announced

Graph Theory

Types of Statistical Designs

An added feature at the meetings in Saskatoon will be the Colloquium which, along with the general theme of "Combinatorial Mathematics" is attracting the attention of mathematicians in othe $r$ countries and promises to make these sessions more international in character. The Colloquium will feature hour or half-hour lectures by invited lecturers once or. twice a week during the seminar.

Another summer activity which will be sponsored by the Congress is a Symposium on Statistics to be held at McGill University from August 15 to August 20. This project originated with Professor G. P. Patil of McGill University, who is carrying through all the arrangements and has organized the symposium a round a group of 
distinguished statisticians, who will discuss Classical and Contagious Discrete Distributions. Among the twenty six statisticians who expect to attend are, 18 from the United States, 3 from Canada, 2 from England, 2 from India, and 1 from Australia. Grants to cover expenses have already been awarded by the National Research Council, the Canadian Nathematical Congress, and McGill University, and a request is also being considered by the National Science Foundation.

Preparations are now being made for the annual high school competitions in eight provinces. Over three thousand students entered the competitions during the past year, in which the Congress awarded prizes or scholarships or both, and, in addition, about four thousand in Ontario and Quebec entered the competition conducted by the Mathematical Association of America and the Society of Actuaries. This was also sponsored by the Canadian Mathematical Congress. With four years' experience in most of these competitions, it seems that an evaluation of results could be made. The Secretariat hopes to have some relevant statistics prepared in time for the September is sue.

Our membership is now approaching the five hundred mark. In addition there are over two hundred subscribers to the Bulletin. In January, the Secretariat made a special effort to contact all the members of mathematics departments in the various universities in Canada, who are not members of the Congress, with the thought that it would help our cause substantially when approaching business and industry for financial support, if we could show solid support from all the mathematicians. The question of this support is frequently raised and although good, it is not by any means complete. Two of our members in the University of Alberta and Memorial University voluntarily assisted by gathering the memberships from their colleagues. Perhaps this could be done in the other universities.

The special note in this issue concerning the Australian Mathematical Society is of interest in considering the progress of that organization. It seems that the Canadian Mathematical Congress provided some inspiration for the Australian Society and two of our past presidents, R. L. Jeffery and G. de B. Robinson, who visited Australia took an active interest in its formation.

L. F.S. Ritcey 